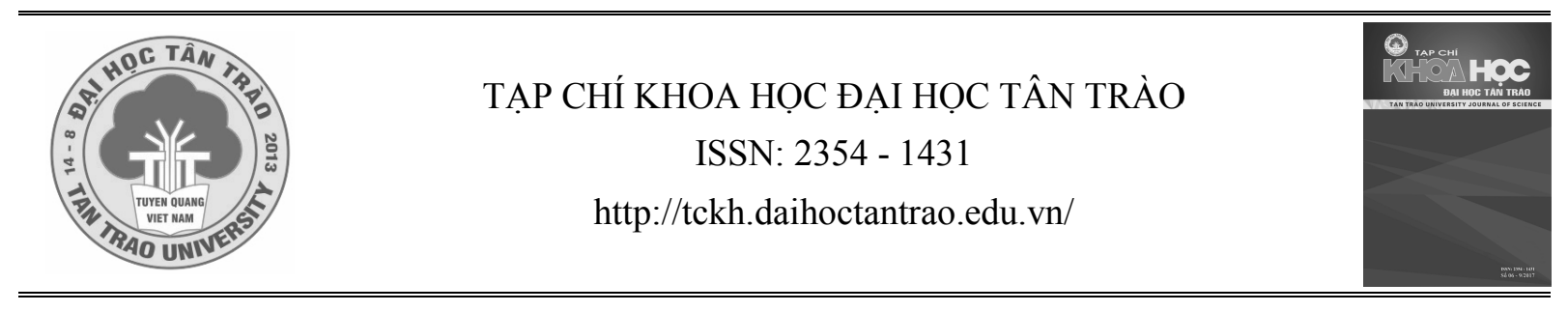

\title{
Đinh Công Thuỷ - gương mặt triển vọng của thơ trẻ xứ Tuyên
}

\author{
Trần Thị Lệ Thanh ${ }^{a *}$; Lê Thời Tân ${ }^{b}$ \\ ${ }^{a}$ Truoòng Đại học Tân Trào \\ ${ }^{b}$ Đại học Thủ Đô Hà Nộ \\ *Email:lethanhcdtq@gmail.com
}

\section{Thông tin bài viết}

Ngày nhận bài:

26/01/2018

Ngày duyệt đăng:

$10 / 3 / 2018$

\section{Tù̀ khoá:}

Đinh Công Thüy;

Tho Tuyên Quang;

Tho trẻ xút Tuyên.

\section{Tóm tắt}

Đinh Công Thủy thuộc lớp nhà thơ trẻ xuất hiện khá muộn trong văn học Tuyên Quang thời kỳ đổi mới. Với 46 tuổi đời và gần hai chục năm cầm bút anh đã cho ra đời nhiều tác phẩm thơ có giá trị, để lại ấn tượng trong lòng bạn đọc. Bài viết trên cơ sở tìm hiểu cuộc đời và sự nghiệp sáng tác cả nhà thơ, tiến hành tìm hiểu những đặc điểm nổi bật của thơ Đinh Công Thủy, nhằm giới thiệu với bạn đọc một gương mặt thơ vừa dung dị đằm thắm, vừa trẻ trung, độc đáo và đầy sáng tạo. Đây cũng có thể xem là những đánh giá ban đầu về những thành tựu và đặc điểm thơ Đinh Công Thủy.

\section{1. Đặt vấn đề}

Trong thời kỳ đổi mới (1986 - 2005), văn học Tuyên Quang đã tồn tại và phát triển khá bề thế với cả số lượng và chất lượng. Chỉ tính riêng thơ đã có tới hơn 3000 bài của hơn 100 tác giả thuộc nhiều thế hệ khác nhau. Nhiều tác giả thơ Tuyên Quang thời kỳ này như: Lê Na, Mai Liễu, Ngọc Hiệp, Cao Xuân Thái, Đinh Công Thuỷ, Tạ Bá Hương... đã từng giành được những giải thưởng trong và ngoài nước. Nhà nhơ Đinh Công Thủy thuộc thế hệ thứ hai của thời kỳ đổi mới. Tuy tuổi đời chưa nhiều, nhưng anh đã có gần hai mươi năm cầm bút. Những tác phẩm Đinh Công Thủy đem đến đều gây ấn tượng cho người đọc. Tiếp cận thơ Đinh Công Thủy, chính là tiếp cận với một tư duy thơ trẻ trung, độc đáo của Tuyên Quang, từ đó có những đánh giá thỏa đáng hơn về các gương mặt thơ Tuyên Quang thời kỳ đổi mới.

\section{Nội dung nghiên cứu}

\subsection{Vài nét về nhà tho Đinh Công Thủy}

Đinh Công Thủy sinh năm 1972 tại Tuyên Quang. Bút danh: Công Sáng. Anhquê gốc ở xã Khánh Phú, huyện Yên Khánh, tỉnh Ninh Bình. Hiện đang công tác Báo Tân Trào. Đinh Công Thủy là hội viên Hội Văn học Nghệ thuật Tuyên Quang, hội viên Hội Văn học Nghệ thuật các Dân tộc thiểu số Việt Nam, hội viên Hội Nhà báo Việt Nam. Đinh Công Thủy vào đời rất sớm. Từ tuổi thiếu niên đã lăn lộn ngược xuôi mọi miền và làm qua nhiều nghề - từ đóng gạch cho đến buôn bán. Mười tám tuổi tác giả nhập quân ngũ. Đọc những tác phẩm thơ nhẹ dịu cảm xúc dung dị của anh thực khó mà hình dung được tác giả của nólà người sớm bươn chải với đời, từng nay đây mai đó. Tập thơ sớm nhất của anh nhan đề Khi tôi lớn xuất bản năm 2000. Năm năm sau nhà thơ xuất bản tập thứ hai Giấc mo hạt thóc. Tập thơ xuất bản gần đây nhất là tập Và trở về bé nhỏ (2009). Bạn đọc gần xa cũng có thể tìm thấy tên Đinh Công Thủy trong các hợp tuyển Tho Tuyên Quang (1988 - 1992); Chút huoong rùng, 1997; Bài ca người thọ, 1998; Tho trẻ chọn lọc (1994 - 1998); Dọc sông Hồng, 2002. Ngoài ra nhà thơ cũng là tác giả của nhiều bài kí, phóng sự, tiểu luận về văn hoá, văn học công bố trên báo Tân Trào và báo Trung ương.anh thực khó mà hình dung được tác giả của nó

\subsection{Nhũ̃ng đặc điểm nổi bật của tho Đinh Công}

\section{Thủy}

\subsubsection{Suy tư trũ tình dung dị mà đằm thắm}

Đinh Công Thủy có câu thơ hòa quyện ý vị triết lí vào trong những hình tượng giàu tính cách ngôn "Vàng chìm, cát nổi, sao rơi; Xác tôi phàm tục, hồn tôi trăng đèn". Nhưng đừng tưởng anh viết cầu kì, đẽo gọt. Thực ra ngược lại, phần lớn các bài thơ mà anh 
viết ra là viết trong tư thế mà anh từng tự bạch " $k h i$ đặt bút nhu thể lấy tù trong túi áo ngực ra". Nói chung, thơ Đinh Công Thuỷ dung dị, chân thực nhưng cũng tràn đầy suy tư chiêm nghiệm về lẽ sống, về nhân sinh.

Đinh Công Thủy là một tác giả trẻ đầy triển vọng của thơ Tuyên Quang xuất hiện sau thời kì đổi mới 1986 đến nay. Trong số những gương mặt trẻ cùng trang lứa thường hồn nhiên hát khúc ca say mê và trong trẻo của thế hệ mình như Tạ Bá Hương, Vũ Công Định, Hoàng Kim Yến, Nguyễn Hải Yến... Đinh Công Thủy nổi bật lên bởi chất suy tư đằm sâu và một giọng điệu riêng không dễ lẫn. Người làm thơ trẻ tuổi này, kỳ lạ thay nhìn cuộc đời bằng một đôi mắt già dặn trước tuổi, chất hồn nhiên vẫn có ở khát khao kiếm tìm và khám phá mà những người trẻ tuổi đều không thể thiếu, nhưng ngay trong những khát khao thường tình này, Đinh Công Thủy đã gửi vào đấy những chiêm nghiệm triết lí nhiều ưu tư và ngậm ngùi. Điều đó thường ít gặp ở những người trẻ tuổi mới làm thơ. Nhưng triết lí trong thơ Đinh Công Thủy không phải thứ triết lí "lấy từ sách triết" mà là một triết lí có gốc rễ từ nỗi thuoong nhớ đồng quê. Đó dường như là sự suy tư về đất, về đồng, về quê nghèo:

"Ở duoói gốc rạ là bùn,

Hanh hao một vết chân buồn - Mẹ tôi

Vục tay xuống vũng mồ hôi

Mấy khi biết ở trên trời là mây

Khom khom bên cạh luống cày

Chai sần thêm nhũ̃ng vết chầy trợt da."

\section{(Giấc mo hạt thóc)}

Nếu chỉ có nỗi nhớ một thủa ấu thơ và niềm thương về người mẹ thì bài thơ sẽ không đọng lại trong lòng ta những dư vị đắng chát đến thế và nó cũng chẳng khác bao nhiêu với rất nhiều bài thơ cùng chủ đề xuất hiện khá nhiều trong trang báo hàng ngày. Nhưng chúng ta giật mình khi đọc những câu thơ mang tính triết lí và chiêm nghiệm về lẽ dại - khôn của kiếp người khi đếm thời gian trôi qua đời mình:

"Tôi theo ra cánh đồng gầy

Cú đôn đáo đuổi theo bầy giẽ giun

Tuổi đi sấp mặt chuồn chuồn

Bước khôn, bước dại, buớc buồn, buớc vui..."

(Giấc mo hạt thóc)

Câu thơ "Tuổi đi sấp mặt chuồn chuồn" là một câu thơ tài hoa: Tuổi thơ được khắc họa bằng biểu tượng "chuồn chuồn" - con chuồn chuồn vô tư bay liệng trong tâm trí trẻ em nhà quê với bao trò chơi nơi đồng bãi, nhưng có mấy ai còn để ý chuồn chuồn khi bay thì sấp mặt? Từ hiện tượng tự nhiên có lẽ thường tình ấy, chú bé trong thơ Đinh Công Thủy này đã tỏ ra sớm biết ưu tư bởi "sấp mặt" để cúi đầu ngẫm ngợi về từng năm tháng tuổi thơ trôi qua, về những nhọc nhằn của mẹ đánh đổi cho con sự trưởng thành hôm nay. Câu thơ "Bước khôn, bước dại, bước buồn, buớc vui..." hay ở cách ngắt nhịp $2 / 2 / 2 / 2$, cách ngắt nhịp ấy tượng hình cho từng bước chân chập chững của chú bé nhà quê trên đường đời không bằng phẳng. Chúng ta ít gặp những suy tư mang tính chiêm nghiệm như thế trong thơ trẻ hôm nay.

Đặc biệt hai câu thơ kể trên của Đinh Công Thuỷ cứ làm cho ta nhớ đến bài thơ lục bát nổi tiếng của nhà thơ Đồng Đức Bốn dù trong một liên tưởng xa mờ:

"Chăn trâu đốt lỉa trên đồng

Rạ rơm thì it gió đông thì nhiè̀u

Mải mê đuổi một con diè̀u

Củ khoai nuớng để cả chiều thành tro."

(Chăn trâu đốt lỉa)

Trong bài thơ Khúc hát nhũng cây rơm ngoài những sáng tạo mới mẻ về ngôn từ như "mồ hôi rơm", "ý nghĩ rom", Đinh Công Thủy không dừng lại ở một "lối mòn" quen thuộc khi miêu tả rơm gắn bó với người nông dân trong cuộc đời lam lũ của họ:

"Àu o chiều ngân nga

Nhũng cây rom thay nguoòi tính vu

Không thấy rơm hát ca

Không thấy rơm cằn nhằn đồng gần đồng $x a$

thửa vuông, thứa méo

Mồ hôi rom nhăm vào vai áo

Thủa rom khô vuoong vất đuoòng vàng

Àu o chiều thênh thang

Nhũng cây rơm đứng buồn

Bếp tàn rơm bát canh chua lấm tấm

Khói rơm thơm ấm ấm trên đầu"

(Khúc ru nhũng cây rơm)

Đinh Công Thủy đã vượt qua những lối mòn quen thuộc ấy để chiêm nghiệm, triết lí về sự hi sinh thầm lặng của rơm cho người, và sự hi sinh thầm lặng của người nông dân cho cuộc sống con người.

"Áu o chiều mênh mông

Nhưng cây rơm không khóc đứng buồn

Ý nghĩ rơm phủ lên đồng đất

Rom cha, rom con

Rom cháu, rom chắt 
Âm thầm chò cuộc hóa sinh..."

(Khúc ru nhũng cây rơm)

Tiêu biểu cho phong cách triết lí chiêm nghiệm trong thơ là bài Khúc tư sụ. Nhà thơ không chỉ nhớ mà còn thương yêu cuộc sống nơi thôn quê bình yên tuy đói nghèo của mình. "Tôi yêu cái võng đầu hồi", "tôi yêu khúc ngoặt dòng sông"... nếu chỉ có vậy thì đây chỉ là bài thơ trung bình nằm trong dòng thơ hoài niệm tuổi thơ nơi thôn quê mà bao nhà thơ Việt Nam đã từng viết. Nhưng đến những câu thơ sau của Đinh Công Thủy thì những triết lí nhân sinh sâu sắc được đúc rút từ chiêm nghiệm cá nhân làm chúng ta giật mình:

"Tôi yêu khúc ngoặt dòng sông

Bồi đi lở lại nhu phong ba đời

Vàng chìm, cát nổi, sao roì...

Xác tôi phàm tục, hồn tôi trăng đèn."

(Khúc tụ sư)

Hai câu thơ đầu còn quá vụng về non nớt mà người mới tập làm thơ nào cũng viết được. Nhưng đến hai câu thơ sau thì phải là người có tài năng và sống hướng nội giàu suy tư mới có thể chạm đến.

Câu thứ nhất ngắt nhịp 2/2/2 với ba hiện tượng tự nhiên ai cũng thấy mà mấy ai biết ngẫm ngợi về nó? Ba danh từ "vàng", "cát", "sao" kết hợp với ba động từ "chìm", "nổi", "rơi”, vừa diễn tả một quy luật buồn của cuộc sống: cái tốt đẹp qua biểu tượng "vàng" thì "chìm" bởi khó nhận biết, cái tầm thường qua biểu tượng "cát" trong sóng thác thường lại cuộn nổi lên trên mặt nước, những ước mơ của con người qua biểu tượng "sao" lại thường rơi rụng...

Đáng trân trọng thay khi con người đang soi chiếu nhìn ngắm chính mình để nhận ra sự phàm tục của thân xác trong đời sống thường ngày với cơm áo mưu sinh, và sự cao đẹp của tâm hồn anh ta trong cuộc sống tinh thần. Sự sóng đôi giữa "phàm tục" và "thanh cao" ấy chẳng phải vẫn diễn ra hàng ngày trong cuộc sống của chính chúng ta hay sao?!

Trong bài thơ Mura II những triết lí tưởng rất cũ vẫn được biểu hiện bằng những ngôn từ mới, thi ảnh mới của Đinh Công Thủy:

"Ngồi mưa nghe gió vù qua

Lúa đồng rạp xuống để mà đứng lên

Gió sàn sạt sát mái hiên

Ngói xô vảy cá thôi miên cột kèo

Ngồi mura nghe sét như reo

Rạ rom thì đưng, tre pheo thì oằn

Cây cao tìm chốn nuơng thân

\section{Cỏ gà nhủi xuống duoói chân mà cuời..."}

Trong bão giông sấm sét những gì tưởng cao lớn vững chãi nhất thì hóa ra yếu mềm run rẩy nhất như "Tre pheo, cây cao", những gì tưởng nhỏ nhoi tầm thường nhất thì lại hóa ra kiên cường dẻo dai trong thầm lặng, ví dụ "lúa đồng" "rạ rơm" "cỏ gă"... hình như con người trong cuộc đời đầy thử thách cũng thế!

2.2.2. Hình tuợng cái tôi cô đơn và kiêu hãnh đối diện thế giói đầy thư thách

Trong thơ trẻ Việt Nam đương đại, chúng ta có thể điểm qua những cái tên tiêu biểu như Phan Huyền Thư, Vi Thùy Linh, Nguyễn Bình Phương, Hoàng Chiến Thắng, Thúy Quỳnh, Phạm Văn Vũ...Họ khác nhau rất nhiều nhưng có một điểm tương đồng là họ trẻ: Cô đơn và kiêu hãnh trên hành trình khám phá thế giới và khẳng định cái tôi thi sĩ của mình, Đinh Công Thuỷ cũng nằm trong qui luật chung ấy và ít nhiều đã có những cách biểu hiện của riêng mình và điều đó là đáng quý. Bởi như đại văn hào Nga Trekhov từng nói đại ý Khi một nhà văn trẻ không có cái gì của riêng mình thì nghĩa là anh ta không có gì hết.

Bài thơ Tho viết dọc đường đi khắc họa một hành trình đơn độc, có thể là đường đời, đường thơ của chính nhà thơ:

"Không bị ám ảnh bởi lũ quạ đen xấu xí

Tôi đi

Con đưòng có nhũng chú thỏ lon ton chạy trước

Và những con ốc sên vuợt dốc đằng sau

Không bị ám ảnh bởi nhũng tàn phai huoong sắc

Tôi đi - hoa trải thảm vô ngần

Sau tan tác tả toi rũ cánh

Tôi biết có nhũng bông cúc bất tử ở phía cuối

Con đuờng..."

Cái tôi cô đơn ấy đến với thế giới để khẳng định mình, bất chấp những "thử thách", những va chạm, những lôi cuốn tầm thường:

"Không bị ám ảnh bởi vé đẹp diễm kiều lộng lẫy

Tôi đi qua mê hoặc đàn bà

Nhũng nguoòi đàn bà đã qua thời trinh nư

Nhung còn chút kiêu sa

Va chạm ngược chiều vụn vỡ pha lê

Con đường tôi đi rất thẳng

Không bị ám ảnh bơi buồn đau hay dối gian

Mặc bao chen, tôi nói lời bình yên."

(Tho viết dọc đường đi)

Nhưng đến khổ kết ta bất ngờ lại gặp sự chiêm nghiệm - triết lí quen thuộc ở Đinh Công Thủy: Thật 
khác với những hăm hở, tự tin ở những khổ thơ trên, câu thơ kết có sự ngậm ngùi của nhà thơ khi nhận ra trên hành trình ấy "Nhũng vết mòn không phải ở bàn chân", và những chông gai trên hành trình không chỉ bào mòn mà còn làm phai nhạt ít nhiều những hăm hở tự tin ban đầu kia. Không có nhiều người viết trẻ có những suy tư như thế, bắt đầu cuộc đời đã bước vào hành trình sáng tạo của mình:

Con đường đi không một lần quay lại

Nhũng vết mòn không phải ở bàn chân

Không bị ám ảnh bởi chính mình - số phận

Tôi đi... đầu sương gội trắng dần...

(Tho viết dọc đường đi)

Xuất thân từ đồng quê, nhà thơ đã hóa thân vào rơm rạ, cào cào, bầy chim di cư, chim én, con dế.... để nói lên tiếng nói của tâm hồn của mình. Bài thơ "Lời hát cào cào" cũng đã mượn lời của sinh vật nhỏ nhoi thân thuộc của trẻ em đồng quê ấy để hát lời ca số phận của mình:

"Tuổi tôi nhur chú cào cào

Cứ hăm hở búng chân vào đất tơi

Đã xa cái thuở nằm nôi

Dạ vâng lời mẹ dặn rồi bước đi

Gật đầu nhũng chuyện bất kỳ

Lách ta lách tách giọng bi giọng hài."

Những ngây thơ rồi ngây ngô của cào cào được mượn để diễn tả những vụng dại ban đầu của chú bé Đinh Công Thủy từ làng quê lên thành phố để rồi, cái tôi cô đơn và kiêu hãnh ấy ngắm nhìn những dại khôn, được - mất của chính mình như của người khác phải cô đơn và kiêu hãnh lắm mới có tư thế ngắm nhìn kỳ lạ ấy? Hay phải chăng từ chỗ "Thương người” trước rồi mới đến "thương thân mình"?.

"Thế nên gần hết nữa đời

Tôi cay đắng nếm đủ bùi, ngọt, chua...

người ta cú bảo tôi nhu

Là khôn lộn xuống, dại đưa lên đầu

Truợt chân vào chốn không đâu

Trần gian một nhúm nguò̀i đau đớn cùng..."

(Lời hát cào cào)

Cũng nằm trong mạch cảm hứng này hàng loạt những bài thơ như : Nhũng điều lón lao, Bầy chim di cu, Trước mùa đông, Ý nghĩ bàn chân, Tuổi, Sụ khôn ngoan, Nụ mầm, Khoảnh khắc nhận thêm tuổi, Hai giấc $m o$ la ... đều là những hình thức biểu hiện đa dạng cho cùng mạch nguồn cảm hứng.
Trong bài thơ Chuyển mùa, cái tôi cô đơn và kiêu hãnh ấy đã hóa thân vào bầy chim sẻ - một bầy chim di chuyển từ "cánh đồng sâu" tới "Tới cánh đồng cạn" để đi tìm sự sống. Biết bao nhọc nhằn trên hành trình kiếm tìm sự sống. Phải chăng bầy chim cũng như người?! Niềm tin và sự kiêu hãnh của nhà thơ ngời sáng trong những câu thơ kết để khẳng định: Dù "gió bấc" có lạnh lùng đến đâu thì bầy chim sẻ ấy cũng sẽ vượt qua để về với những cánh đồng đầy hi vọng...

"Cánh đồng đã chuyển vụ màu

Bầy chim sẻ mỏ khoằm lông xù đi đâu

Phía truớc là mùa màng trông đợi

Phía sau

Nơi gờ tuờng còn vương sợi rơm màu mục oải

Líu ríu bài ca trong tiềm thức

Mùa này

Nhũng đôi cánh nhỏ nhoi đang bươn qua gió bấc".

Trong cuộc trả lời phỏng vấn trên tạp chí văn nghệ quân đội năm 2008 nhà thơ Nguyễn Bình Phương đã nhận xét đại ý như sau về thơ Việt đương đại: “Các nhà tho già thì viết về tình yêu, các nhà tho trẻ chura sống đuợc bao nhiêu thì lại hăm hở triết li’”. Chúng tôi nghĩ nên hiểu nhận xét của Nguyễn Bình Phương như một đánh giá khách quan về thực trạng thơ Việt đương đại chứ không nên hiểu là một lời chê trách, vì đã là nhà thơ thì dù ở độ tuổi nào cũng có thể viết về tình yêu và cũng có thể triết lí. Điều quan trọng là họ viết về tình yêu và triết lí có đúng và hay không. Nhà thơ Đinh Công Thủy là người già dặn trước tuổi và hồn thơ ấy ngắm nhìn cuộc đời và triết lí như một tất yếu, một nhu cầu không thể khác của hồn thơ này như cây hoa hồng thì phải sinh ra hoa hồng, và họa mi thì phải hót tiếng hót của họa mi:

"Trong đời sống văn nghệ vài năm gần đây, nhiều cây viết trẻ thế hệ@ đang cố gắng tìm tòi cho mình một lối tho riêng. Các trào luu Hiện đại, Hậu hiện đại...đã đập võ lối truyền thống, làm cho khuôn mặt tho biến dạng đi rất nhiều. Song ở tác giả trẻ Đinh Công Thuỷ, độc giả vẫn nhận ra anh neo bám vào lối đi truyền thống, tù đó tạo ra nhũng giá trị mói theo cách của riêng anh, kết hợp khá nhuần nhuyễn cảm quan tu duy tho hiện đại."

\subsubsection{Tu duy làng quê độc đáo}

"Vệt thời gian

Chơi trò đuổi bắt

Một sáng dậy

Theo nhau hằn lên đôi mắt mối người."

(Một sáng dậy) 
Có thể nói, thơ Đinh Công Thủy là sự trăn trở, suy ngẫm về thời gian. Thời gian là một tầng khai thác về trạng thái tinh thần của con người mà nhà thơ thể hiện trong thơ ca của mình. Với ý thức về sự hữu hạn của đời người, thời gian trở thành nỗi ám ảnh của con người, trở thành thi hứng của nhà thơ. Sự cảm nhận "thời gian lặng rót một dòng buồn tênh" của Lưu Trọng Lư vào đầu thế kỉ XX có chút gì vu vơ mơ hồ, khó xác định. Với Đinh Công Thủy, thời gian được cảm nhận cụ thể biết bao "tâm trạng": "Thời gian đi như một cuộc trốn tìm" (Đi thành phố).

Con người thường ngưỡng vọng tới chốn vĩnh hằng, muốn vượt qua sự ràng buộc nghiệt ngã của trần gian nhưng lại ý thức được về sự hữu hạn của đời người "Thời gian trên ngón tay" (Thế là ...).

Ý niệm thời gian trong thơ Đinh Công Thủy cụ thể hóa thành tâm trạng với những hồi tưởng về quá vãng:

"Đến bây giò̀ trải rộng phía xa khơi
Cút mong bóng con đò nào đến cập
Đò vắng rồi! Bến ẩn mình con nước
Giấu chút bẽ bàng

Thầm gọ!!

Nhơ thuong ơi!"

(Hồn bến)

Và với những hoài niệm về làng quê - một làng quê nông thôn, Đinh Công Thủy không xuất thân từ nông thôn mà xuất thân trong một gia đình văn nghệ, bản thân đích thị là sản phẩm của thời hiện đại... vậy mà tác giả lại dành nhiều cảm xúc cho làng quê:

"Thôi em về lại làng quê

Tìm chi cát bụi ngu ngo thị thành

Chiều quê ngọn gió ngọt lành

Vuò̀n sau vẫn khóm giành giành nở hoa."

\section{(Thôi em về lại)}

Đọc đoạn thơ trên, lòng chúng ta không khỏi chộn rộn, bồn chồn... Phải chăng tiếng gọi của quê hương, của làng quê cứ hiện dần trong ký ức - ký ức một thời quá khứ "với ngọn gió ngọt lành" cùng với "khóm giành giành nở hoa". Câu thơ như lời nhắn gửi, hối thúc, giục giã "em" hãy trở về, trở về làng quê "Tìm chi cát bụi ngu ngơ thị thành".

Ở đó có những người nông dân "chân quê", chân lấm tay bùn "bán mặt cho đất, bán lưng cho trời". Chắc hẳn chúng ta vô cùng xúc động khi nghe nhà thơ bày tỏ tình cảm của mình với cuộc sống đồng ruộng và hơn thế còn bộc lộ thái độ cảm thông với những vất vả nhọc nhằn, lam lũ của người nông dân. Trong bài “Chạm ký úc lòng”, anh viết:

\section{"Làng}

Phập phồng vết chân trâu

Sấp mặt chiêm mùa

Chân nẻ tay chai

Mặt người thời gian nhiều hơn tuổi".

ơ đó là nhũng ký ức tuổi tho với nhũng hình ảnh gần gũi, thân thuoong:

"Nhũng gốc lúa thấp thỏm đọi mùa

Mảnh bùn cong bánh đa khô

Nhũng mà ếch hang cua sâu hoằm”.

Mong ngóng "cánh chuồn xuống thấp" và mơ “tiếng sấm ì ầm xa lắc".

Ở đó có hình ảnh người mẹ thân yêu - một người mẹ nông dân làm ruộng "Mồ hôi rơi dọc theo xá cày... gan bàn chân nứt toác" (Phác thảo gia đình).

Sự thành công trong thơ Đinh Công Thủy là những trang viết về mẹ. Đó là những cảm xúc chân thành tha thiết, biết ơn xen lẫn ăn năn của những người con vì mải mê công việc mà quên lãng, vô tình với người mẹ thân yêu của mình:

“Con mê mải lập trình nhũng điều vô nghĩa lý

Chợt giật mình khi biết gió rung cây”.

$$
\text { (Viết tặng ngày sinh nhật mẹ) }
$$

Từ chỗ "giật mình" thảng thốt, nhà thơ đã giành sự yêu thương, quan tâm, sẻ chia, thông cảm với mẹ:

“ở dưới gốc rạ là bùn

Hanh hao một vết chân buồn - Mẹ tôi”.

Vục tay xuống vũng mồ hôi

Mấy khi biết ở trên trời là mây

Khom khom bên cạnh luống cày

Chai sần thêm nhũng vết trầy trợt da

Chiêm mùa thoăn thoắt đi qua

Thảnh thơ chỉ một câu à ơi ru ... !’”

\section{(Giấc mo hạt thóc)}

Mấy câu thơ "ở duới góc rạ là bùn. Hanh hao một vết chân buồn - Mẹ tôi" đọc lên nghe thật cảm động, nghe thật tội nghiệp, cay đắng. Mà tội nghiệp cay đắng vốn là hình ảnh quen thuộc của các bà mẹ xưa.

Xưa nay, thơ vốn là tiếng nói của đời sống cá nhân, của những cõi miền riêng tư. Thơ là tiếng nói nhạy cảm nhất của tình cảm, của trái tim con người. Tình yêu là chủ đề muôn thuở, là đối tượng khai thác không bao giờ cạn kiệt trong cảm hứng thi ca. Đinh Công Thủy hồi tưởng, nuối tiếc sự lỡ làng hoặc sự muộn màng:

"Chị về chốn ấy - theo chồng 
Câu tho bỏ dở giṽua chùng... đành thôi

Chị về chốn ấy xa xôi

Có bao giờ biết một người nhớ mong”.

(Bài tho viết cho một người)

Có lẽ vì chậm muộn, lỡ làng mà lỡ luôn cả cơ hội làm nên hạnh phúc, và không ít lần sự chậm muộn, lỡ làng để lại niềm tiếc nuối, ngẩn ngơ:

“ Thôi tù̀ giã một hoàng hôn diệu vợi

Mảnh trăng theo về - thăm thẳm nhớ nhung

Ta với em và hoàng hôn nhu thế

Huơng trong tay vuơng vấn khôn cùng”.

(Chiều say)

Có cảm giác như Đinh Công Thủy luôn muốn gắn mình với làng quê. Xa rời nó, chìm lấp trong những xô bồ phố xá anh sợ sẽ đánh mất mình. Tuy nhiên, dù đã được nhiều thành công với đề tài nông thôn như thế, nhưng Đinh Công Thủy không nằm lỳ ở nông thôn để say sưa ngòi bút với cây rơm, gốc rạ, rất nhiều bài thơ tác giả đã quay về trò chuyện với trái tim mình. Trong thơ anh hiện lên những băn khoăn đầy trắc ẩn về những vấn đề đời tư, thế sự.

Đó là cảnh ngang trái, trớ trêu ở đời. Trong “Anh hề và người khóc mướn", tác giả đã lên án phê phán sự giả dối của con người trong xã hội:

"Tôi cuời - Anh khóc - Thế thôi!

Hai ta cùng một kiếp ngưòi - giản đơn”.

Nhung vì miếng com, manh áo:

"Nghề hai ta có khác chi

Kẻ cuời, người khóc
Cüng vi

Miếng cơm”.

Hay có khi nhà thơ đưa ra một lời khuyên - một lời nhắn nhủ nhẹ nhàng mà ấm lòng biết bao người con gái:

"Thôi em về lại cái hồi

Áo nâu, chân đất, mồ hôi lấm bùn

Đong đưa má lúm đồng tiền

Gàu sòng khỏa nhũng hờn ghen mắt chò̀”.

Và "giá mà”... "giá đù̀ng” thì đâu đến nỗi:

"Nhẫn trao, áo cuóoi... qua cầu vô duyên".

(Thôi em về lại)

Thơ Đinh Công Thủy gắn bó với mảnh đất quê hương. Thơ anh có một giọng điệu mộc mạc, phóng khoáng, một tình cảm dào dạt trong sáng. Thơ anh là thơ của tình yêu làng quê, tình cảm gia đình, tình yêu đôi lứa, và cả những khúc mắc buồn vui trong cuộc đời.

\section{Kết luận}

Công chúng thơ ở mọi thời đại đều giống nhau ở một điểm. Họ cần những nhà thơ có tâm và có thực tài. Họ mong muốn phát hiện những bài thơ hay, những gương mặt thơ có triển vọng. Nhà thơ Đinh Công Thuỷ với những gì đạt được hôm nay, chắc con đường thơ sẽ còn rất dài. Có thể ai đó còn cho rằng không nên phân biệt thơ già - thơ trẻ mà chỉ nên phân biệt thơ hay - thơ dở mà thôi. Tuy nhiên với Đinh Công Thủy, nhiều người sẽ tìm thấy ở anh cả những bài thơ hay và cả gương mặt thơ trẻ trung đầy triển vọng./.

\section{Dinh Cong Thuy - A potential face of Tuyen Quang poetry}

Tran Thi Le Thanh; Le Thoi Tan

\section{Article info}

Recieved:

26/01/2018

Accepted:

$10 / 3 / 2018$

Keywords:

Dinh Cong Thuy;

Tuyen Quang poem;

Tuyen Quang new poem.

\begin{abstract}
Dinh Cong Thuy is a young poet who appears rather late in the literature of Tuyen Quang. With 46 years of age and nearly twenty years of writing he has written many valuable poetry works that leave an impression in the hearts of readers. The article is based on the study of the life and work of the poet, the purpose of investigating the outstanding features of Dinh Cong Thuy poetry is introducing readers a simple and thoughtful poetic face which is unique and creative. This can be considered as the initial assessment of the achievements and characteristics of Dinh Cong Thuy poetry.
\end{abstract}

